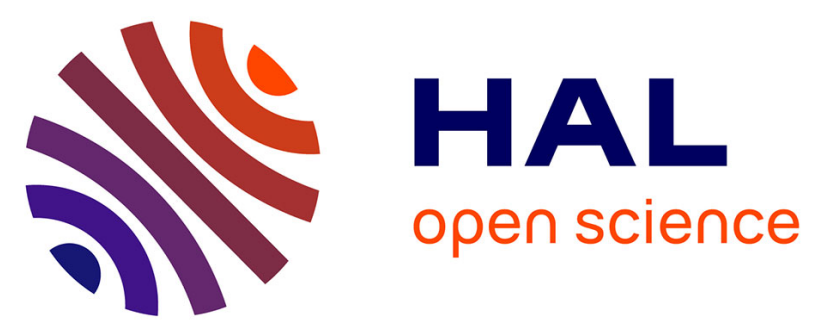

\title{
Management of patients with inflammatory bowel disease and spondyloarthritis
}

\author{
Lieven Pouillon, Peter Bossuyt, Joke Vanderstukken, David Moulin, Patrick \\ Netter, Silvio Danese, Jean-Yves Jouzeau, Damien Loeuille, Laurent \\ Peyrin-Biroulet
}

\section{To cite this version:}

Lieven Pouillon, Peter Bossuyt, Joke Vanderstukken, David Moulin, Patrick Netter, et al.. Management of patients with inflammatory bowel disease and spondyloarthritis. Expert Review of Clinical Pharmacology, 2017, 10 (12), pp.1363-1374. 10.1080/17512433.2017.1377609 . hal-01715137

\section{HAL Id: hal-01715137 \\ https://hal.univ-lorraine.fr/hal-01715137}

Submitted on 22 Feb 2018

HAL is a multi-disciplinary open access archive for the deposit and dissemination of scientific research documents, whether they are published or not. The documents may come from teaching and research institutions in France or abroad, or from public or private research centers.
L'archive ouverte pluridisciplinaire HAL, est destinée au dépôt et à la diffusion de documents scientifiques de niveau recherche, publiés ou non, émanant des établissements d'enseignement et de recherche français ou étrangers, des laboratoires publics ou privés. 


\section{Management of patients with inflammatory bowel disease and spondyloarthritis}

\section{Lieven Pouillon, Peter Bossuyt, Joke Vanderstukken, David Moulin, Patrick} Netter, Silvio Danese, Jean-Yves Jouzeau, Damien Loeuille \& Laurent PeyrinBiroulet

To cite this article: Lieven Pouillon, Peter Bossuyt, Joke Vanderstukken, David Moulin, Patrick Netter, Silvio Danese, Jean-Yves Jouzeau, Damien Loeuille \& Laurent Peyrin-Biroulet (2017): Management of patients with inflammatory bowel disease and spondyloarthritis, Expert Review of Clinical Pharmacology, DOI: 10.1080/17512433.2017.1377609

To link to this article: http://dx.doi.org/10.1080/17512433.2017.1377609

Accepted author version posted online: 07 Sep 2017.

Submit your article to this journal $\square$

Q View related articles $₫$

View Crossmark data \lceil 
Publisher: Taylor \& Francis

Journal: Expert Review of Clinical Pharmacology

DOI: $10.1080 / 17512433.2017 .1377609$

\section{Review}

Management of patients with inflammatory bowel disease and spondyloarthritis

Pouillon, Lieven (1), Bossuyt, Peter (2), Vanderstukken, Joke (3), Moulin, David (4), Netter, Patrick (5), Danese, Silvio (6), Jouzeau, Jean-Yves (7), Loeuille, Damien (8), Peyrin-Biroulet, Laurent $(9)^{\circ}$

(1)

Department of Hepato-Gastroenterology, University Hospital Leuven

Uz Gasthuisberg Leuven, Herestraat 49, 3000 Leuven, Belgium

E-mail: lievenpouillon@icloud.com

(2)

Imelda GI Clinical Research Centre

Imeldaziekenhuis Bonheiden, Imeldalaan 9, 2820 Bonheiden, Belgium

E-mail: peter.bossuyt@imelda.be

(3)

Department of Immunology-Allergology-Rheumatology, University Hospital Antwerp

University Hospital Antwerp, Wilrijkstraat 10, 2650 Edegem, Belgium

E-mail: jokevanderstukken@hotmail.com 
UMR 7365 IMoPA CNRS-Université de Lorraine, Biopôle de l'Université de Lorraine, Campus Biologie-Santé, Vandœuvre-lès-Nancy Cedex, France. CHU de Nancy, Contrat d'interface, Nancy, F-54035, France

E-mail: david.moulin@univ-lorraine.fr

UMR 7365 IMoPA CNRS-Université de Lorraine, Biopôle de l'Université de Lorraine, Campus Biologie-Santé, Vandœuvre-lès-Nancy Cedex, France E-mail: gotheilnetter@yahoo.fr

(6)

Department of Biomedical Sciences

Humanitas University, Via Manzoni 113, 20089 Rozzano, Milan, Italy

E-mail: sdanese@hotmail.com

(7)

UMR 7365 IMoPA CNRS-Université de Lorraine, Biopôle de l'Université de Lorraine, Campus Biologie-Santé, Vandœuvre-lès-Nancy Cedex, France

E-mail: jean-yves.jouzeau@univ-lorraine.fr

(8)

Department of Rheumatology, Nancy University Hospital

Université de Lorraine, Nancy 1, Allée du Morvan, 54511 Vandœuvre-lès-Nancy, France E-mail: d.loeuille@chru-nancy.fr 
(9)

Inserm U954 and Department of Gastroenterology, Nancy University Hospital

Université de Lorraine, Nancy 1, Allée du Morvan, 54511 Vandœuvre-lès-Nancy, France

Phone: + 33383153361 / Fax: + 33383153633

E-mail: peyrinbiroulet@gmail.com

${ }^{\circ}$ Corresponding author

\begin{abstract}
Introduction: More than half of the patients with inflammatory bowel disease (IBD) experience at least one extra-intestinal manifestation (EIM). The most common EIM in patients with IBD is spondyloarthritis (SpA). Microscopic intestinal inflammation is documented in almost $50 \%$ of the patients with $\mathrm{SpA}$.
\end{abstract}

Areas covered: We give an overview of the classification, the epidemiology and the diagnosis of IBD and SpA. The treatment goals, the pharmacologic management options and the available treatment guidelines in IBD patients with SpA are discussed.

Expert Commentary: The coexistence of IBD and SpA generates challenges and opportunities for both the gastroenterologist and the rheumatologist. The potential of drugs with a gut-specific mode of action in the treatment of IBD-related arthritis warrants further exploration.

\title{
Keywords
}


Crohn's disease, Inflammatory bowel disease, Spondyloarthritis, Treat-to-target, Ulcerative colitis

\section{Abbreviations}

AS: ankylosing spondylitis; ASAS: Assessment in SpondyloArthritis international Society;

CI: confidence interval; CD: Crohn's disease; CDAI: Crohn's disease activity index; CRP: Creactive protein; DAS: disease activity score; ECCO: European Crohn's and Colitis Organisation; EIM: extra-intestinal manifestation; HLA-B27: human leukocyte antigen B27; IBD: inflammatory bowel disease; JAK: janus kinase; MDA: minimal disease activity; MRI: magnetic resonance imaging; nr-axSpA: non-radiographic axial spondyloarthritis; NSAID: non-steroidal anti-inflammatory drug; SpA: spondyloarthritis; TNF: tumor necrosis factor; RA: rheumatoid arthritis; r-axSpA: radiographic axial spondyloarthritis; UC: ulcerative colitis; US: ultrasound; uSpA: undifferentiated spondyloarthritis

\section{Introduction}

Crohn's disease (CD) and ulcerative colitis (UC) are chronic disabling conditions ${ }^{1,2}$. More than half of the patients with IBD experience at least one extra-intestinal manifestation $(\mathrm{EIM})^{3}$. The most common EIM in patients with IBD is spondyloarthritis (SpA) ${ }^{4}$. SpA is a group of diseases with similar clinical, radiological and serological features. It includes ankylosing spondylitis (AS), also defined as radiographic axial SpA (r-axSpA), nonradiographic axial $\mathrm{SpA}(\mathrm{nr}-\mathrm{axSpA})$, psoriatic arthritis, reactive arthritis, IBD-associated SpA and undifferentiated $\mathrm{SpA}(\mathrm{uSpA})^{5}$. SpA causes a significant burden to the patient and to the society ${ }^{6-9}$. Microscopic intestinal inflammation is documented in approximately $50 \%$ of patients with $\mathrm{SpA}^{10}$, and 7\% of these patients develop IBD ${ }^{11}$. An integrated management of 
patients with coexisting IBD and SpA, with cooperation between the gastroenterologist and the rheumatologist, is necessary to provide the best possible care. Most anti-tumor necrosis factor (anti-TNF) agents work for both diseases ${ }^{12,13}$. Only etanercept, an anti-TNF agent licensed for the use in patients with AS, is not a treatment option in patients with IBD. Ustekinumab, a monoclonal antibody that binds to the p40 subunit of interleukin-12 and interleukin-23, proved efficacy in patients with $\mathrm{CD}^{14}$ and in patients with psoriatic arthritis ${ }^{15}$, but its value in patients with (non-)radiographic axial SpA remains unclear. Whether drugs with a gut-specific mode of action, such as vedolizumab, work for IBD-related arthritis is debated.

Herein, we give an overview of the classification, the epidemiology and the diagnosis of IBD and $\mathrm{SpA}$. The treatment goals, the pharmacologic management options and the available treatment guidelines in IBD patients with SpA are discussed. Finally, an expert opinion about the treatment of patients with coexisting IBD and SpA is provided.

\section{Methodology}

We searched for relevant manuscripts in PubMed/MEDLINE, EMBASE (Excerpta Medica Database) and Cochrane CENTRAL from their inception until June $1^{\text {st }}, 2017$. The following keywords were included alone or in combination: 'Crohn's disease', 'ulcerative colitis', 'inflammatory bowel disease', 'spondyloarthritis', 'ankylosing spondylitis', 'epidemiology', 'diagnosis', ‘management', 'treatment goals', ‘treat-to-target', 'corticosteroids', 'aminosalicylates', 'immunomodulators', 'anti-tumor necrosis factor therapy', 'vedolizumab', 'ustekinumab', 'janus kinase inhibitors'. Bibliographies of included articles were searched and experts in IBD and rheumatology were consulted to identify additional studies. Relevant articles published in English were critically reviewed. Priority was given to randomized 
controlled trials and meta-analyses published in the last 5 years. Relevant abstracts presented at major meetings were also considered.

\section{Epidemiology}

A recent meta-analysis assessed the prevalence and incidence of peripheral and axial SpA in IBD patients ${ }^{16}$. The authors included 71 studies reporting on the prevalence of sacroiliitis, AS, arthritis, enthesitis and dactylitis in 27524 patients. SpA occurred in up to $13 \%$ of patients with IBD. A detailed description about the criteria used for diagnosing SpA is lacking, but the authors state that in $56.3 \%$ of the studies 'objective standard criteria for the measurement of SpA' were used and that 'SpA was measured reliable' in $46.5 \%$ of patients. The pooled prevalence of sacroiliitis was $10 \%$ (95\% confidence interval (CI) $8-12 \%)$, the pooled prevalence of AS was 3\% (95\% CI 2-4\%) and the pooled prevalence of peripheral arthritis was $13 \%(95 \%$ CI 12-15\%). The prevalence of sacroiliitis, AS and peripheral arthritis was higher in CD patients compared to UC patients ${ }^{16}$. Earlier data report evidence of radiologic sacroiliitis in $20 \%$ to $50 \%$ of IBD patients ${ }^{17-19}$. In a cohort study with a duration of almost 2 years in a combined gastroenterology-rheumatology clinic, 269/1495 (18\%) IBD patients reported musculoskeletal pain. Enteropathic SpA was diagnosed in 136/269 (50.5\%) of these patients ${ }^{20}$. To establish the diagnosis of enteropathic SpA, clinical and biochemical data were collected and joint imaging, including ultrasound (US) and traditional radiography for the assessment of peripheral involvement (arthritis, enthesitis, dactylitis) and traditional radiography and magnetic resonance imaging (MRI) for the assessment of axial involvement, was requested when appropriate ${ }^{20}$. In a multicenter study evaluating the subclinical affected joint and entheseal involvement by US in 76 patients with IBD, 20 patients with SpA and 45 healthy controls, $84.1 \%$ of IBD patients had at least one entheseal abnormality. The 
prevalence was higher in the IBD patients than in the healthy controls, but there was no difference between the IBD and the SpA patients ${ }^{21}$.

\section{Diagnosis}

\subsection{Diagnosing SpA in IBD patients}

SpA is classified according to the Assessment in SpondyloArthritis international Society criteria, distinguishing peripheral from axial SpA (table 1$)^{22,23}$. The positive predictive value of these sets of criteria is $89.5 \%$ for peripheral $\mathrm{SpA}$ and $93.3 \%$ for axial $\mathrm{SpA}^{24}$. European Crohn's and Colitis Organisation (ECCO) consensus describes a diagnostic approach for arthritis in IBD patients (table 2) ${ }^{3}$. Given the non-erosive character of peripheral arthritis, especially oligoarthritis, conventional radiography is usually normal and the recognition of IBD-related peripheral SpA remains mainly clinical (eg. joint swelling and tenderness) ${ }^{25}$. When clinical exam alone is doubtful, US examination or MRI may be used to confirm peripheral enthesitis or to detect peripheral arthritis, tenosynovitis and bursitis ${ }^{26}$. The diagnosis of axial SpA in IBD patients is based on the combination of inflammatory low back pain associated with conventional radiographic or MRI features of sacroiliitis ${ }^{3}$. Inflammatory back pain must be suspected in the presence of 2 or more of the following features, and the presence of 4 or more of these features are considered diagnostic: onset before 45 years, insidious onset, duration of more than 3 months, morning stiffness more than 30 minutes, improvement with exercise, no improvement with rest, awaking from pain and alternating buttock pain ${ }^{27}$. Added to clinical and biological data, MRI analysis contributes to an earlier diagnosis of axial SpA in patients with $\mathrm{IBD}^{28}$, especially in the subgroup of patients with nraxSpA (ie. axial SpA but without abnormalities of the sacroiliacal joint on conventional radiography). Evidence of bone marrow inflammation, as defined by the ASAS-MRI working group, is required for the definition of active sacroiliitis on MRI ${ }^{29}$. Human leukocyte antigen 
B27 (HLA-B27) positivity is seen in $78 \%$ of patients with IBD and AS ${ }^{17,30}$ and possession of HLA-B27 conveys a very high risk of developing axial inflammation in $\mathrm{CD}^{31}$. Nevertheless, the lower overall prevalence of HLA-B27 positivity in IBD-related SpA as compared to idiopathic SpA, makes HLA-B27 unreliable to be used as a diagnostic test for SpA in IBD patients ${ }^{3,32}$.

SpA symptoms are not always recognized in patients with IBD. A diagnostic delay of SpA in IBD patients of 5.2 years is reported ${ }^{20}$. A Canadian study showed that 129 out of $350(36.9 \%)$ unselected IBD patients had musculoskeletal SpA features meeting the ASAS criteria. Nevertheless, only $51 \%$ of those patients was seen by a rheumatologist. In that group of patients, SpA was diagnosed in 58\% of the cases, while another rheumatic disorder was found in $21 \%{ }^{33}$. Subsequently, patients with symptoms of SpA may be underdiagnosed and effective treatment may be delayed, which can lead to a chronic debilitating disease course and a decreased quality of life ${ }^{34}$. The use of a SpA self-reported questionnaire in IBD patients led to an increased recognition of $\mathrm{SpA}{ }^{35}$. Diagnostic clues that should trigger the gastroenterologist to refer the patient for further rheumatologic evaluation are summarized in table 3 , part $\mathrm{A}^{4,5}$.

\subsection{Diagnosing IBD in SpA patients}

The diagnosis of IBD is made by clinical evaluation and a combination of biochemical, endoscopic, histological and/or radiological data ${ }^{36,37}$. Importantly, IBD can still be asymptomatic at the time that patients present with musculoskeletal symptoms ${ }^{38}$. In a cohort of $65 \mathrm{SpA}$ patients, $46.2 \%$ had microscopic evidence of gut inflammation ${ }^{10}$. Risk factors associated with the presence of microscopic gut inflammation in axial SpA are younger age, progressive disease, male sex and a high disease activity ${ }^{10} .7 \%$ of SpA patients with microscopic gut inflammation develop IBD ${ }^{11}$. Occurrence of EIMs should therefore prompt 
physicians to look for underlying IBD. This is especially important for the detection of CD, where the concept of early intervention is emerging ${ }^{39}$. Diagnostic clues that should trigger the rheumatologist to refer the patient for further gastroenterological evaluation are summarized in table 3, part $\mathrm{B}^{4,5}$. In addition, Cypers et al. demonstrated an association between elevated serum calprotectin and C-reactive protein (CRP) and microscopic bowel inflammation in a cohort of 125 patients with $\mathrm{SpA}^{40}$. Also fecal calprotectin was significantly higher in patients with microscopic bowel inflammation. Calprotectin measurements in stool and serum, in addition to CRP, therefore provide a an extra tool to identify SpA patients at risk of IBD ${ }^{40}$.

\section{Treatment goals}

\subsection{Treatment goals in IBD}

The STRIDE (Selecting Therapeutic Targets in Inflammatory Bowel Disease) consensus defined mucosal healing in combination with resolution of symptoms as one of the major treatment goals for patients with $\mathrm{IBD}^{41}$. Mucosal healing is associated with sustained clinical remission, steroid-free remission, and reduced rates of hospitalization and surgery in $C D^{42,43}$. In UC, studies demonstrated the association of mucosal healing with improved long-term clinical outcomes and a reduced risk of colectomy ${ }^{44-47}$. However, all data available on the value of mucosal healing as a target in IBD are mainly retrospective or circumstantial, and disease-modifying studies in IBD are scarce ${ }^{48}$. Also, the definition of mucosal healing is debated in both CD and UC, and the current definitions, based on cut-offs of endoscopic activity indices, are less favorable to be used as an instrument for disease remission ${ }^{49,50}$. The STRIDE consensus did not retain biomarkers as a treatment target ${ }^{41}$. In the recent CALM study, a treat-to-target strategy based on a composite target of tight control of biomarkers (fecal calprotectin and CRP) and clinical symptoms (Crohn's disease activity index or CDAI) was superior to standard care based on symptom control alone. Significantly more patients 
achieved mucosal healing with absence of deep ulcers after 1 year ${ }^{51}$. In UC, Osterman et al. showed that a calprotectin-guided approach in aminosalicylates treated patients reduced relapse rates ${ }^{52}$. In 52 patients with UC in remission but with fecal calprotectin $>50 \mu \mathrm{g} / \mathrm{g}$ taking multimatrix mesalamine $2.4 \mathrm{~g} /$ day, mesalamine was either continued at the same dose or increased by $2.4 \mathrm{~g} /$ day for 6 weeks. The primary outcome of continued remission with fecal calprotectin $<50 \mu \mathrm{g} / \mathrm{g}$ was achieved by $3.8 \%$ of controls and $26.9 \%$ of the dose escalation group $(\mathrm{p}=0.05)$. More patients in the dose escalation group reduced fecal calprotectin to below $100 \mu \mathrm{g} / \mathrm{g}(\mathrm{p}=0.04)$ and $200 \mu \mathrm{g} / \mathrm{g}(\mathrm{p}=0.005)$. Clinical relapse occurred sooner in patients with fecal calprotectin $>200 \mu \mathrm{g} / \mathrm{g}$ compared to those with fecal caprotectin $<200 \mu \mathrm{g} / \mathrm{g}(\mathrm{p}=0.01)^{52}$. Nevertheless, whether treat-to-target strategies in IBD patients will prevent negative long-term outcomes, such as disability and bowel damage in $\mathrm{CD}$, is yet to be established, whereas in another inflammatory disease such as rheumatoid arthritis (RA), evidence has accumulated over the last decade ${ }^{48,53,54}$

\subsection{Treatment goals in SpA}

Similar to RA and CD, the treatment goals in SpA are maintenance of physical function, control of disease activity and prevention of organ damage ${ }^{55}$. The primary treatment goal of axial SpA is, according to the updated ASAS-EULAR management recommendations, to maximise long-term health-related quality of life trough control of symptoms and inflammation, prevention of progressive structural damage, preservation or normalisation of function and social participation ${ }^{56}$. A predefined target when initiating therapy is recommended to achieve this goal ${ }^{56}$. Recently, the association between disease activity and progression of tissue damage was established in patients with early axial $\mathrm{SpA}{ }^{57}$. Nevertheless potent inflammatory drugs like anti-TNF agents do not prevent disease progression ${ }^{58}$. Treat- 
to-target recommendations in SpA were formulated in 2014 by an international task force, but the investigators admitted evidence base was not strong ${ }^{59}$.

\section{Treatment options}

Current pharmacologic treatment options in patients with IBD are aminosalicylates, corticosteroids, immunomodulators, anti-TNF therapy, vedolizumab, ustekinumab and JAK inhibitors. A schematic overview of the pharmacologic treatment options in patients with IBD and SpA is shown in figure 1. Non-steroidal anti-inflammatory drugs (NSAIDs) are considered a first-line therapy in patients with $\mathrm{SpA}^{22,23}$ and secukinumab, an anti-interleukin17A monoclonal antibody, is a well-established treatment option for $\mathrm{AS}^{60}$. Nevertheless, both have no place in the specific treatment of IBD and will therefore not be discussed separately in this section.

\subsection{Aminosalicylates}

There is a lack of evidence for the use of 5 -aminosalicylates (olsalazine and mesalamine) in $\mathrm{CD}^{61,62}$. Sulfasalazine shows low efficacy for the treatment of active $\mathrm{CD}^{62}$, but its incidental side effects should be taken into account when initiated ${ }^{36}$. Oral 5-aminosalicylates are highly effective for inducing and maintaining remission in mild to moderate $\mathrm{UC}{ }^{63-65}$. Also sulfasalazine is effective in the treatment of $\mathrm{UC}^{66}$.

Sulfasalazine treatment was not more effective than placebo in a 24 -week trial in patients with axial $\mathrm{SpA}^{67}$. A Cochrane review confirmed that there is not enough evidence to support any benefit of sulfasalazine in reducing pain, disease activity, radiographic progression, or improving physical function and spinal mobility in the treatment of $\mathrm{AS}{ }^{68}$. Nevertheless, sulfasalazine can be used for peripheral $\mathrm{SpA}$ since it has demonstrated its efficacy in these patients ${ }^{56,69,70}$. 


\subsection{Corticosteroids}

Two historical trials established corticosteroids as an effective therapy in inducing remission in $\mathrm{CD}^{71,72}$. Both topically (oral budesonide) and systemically acting corticosteroids can be used, depending on the disease distribution and severity. Although good at inducing remission, steroids are ineffective for maintaining remission in $\mathrm{CD}^{36}$. In $\mathrm{UC}$, systemic corticosteroids are appropriate in patients with moderate to severe activity and in those with mild activity who do not respond to mesalamine. Topical acting oral steroids (beclomethasone dipropionate) can also be used in patients with mild to moderately active disease ${ }^{66}$. Furthermore, budesonide foam induces remission in patients with mild to moderate ulcerative proctitis and proctosigmoiditis ${ }^{73}$. In acute severe UC, intravenously administration of methylprednisolone $60 \mathrm{mg}$ each 24 hours or hydrocortisone $100 \mathrm{mg}$ four times daily is promptly warranted ${ }^{66,74}$.

Systemic corticosteroid therapy is not recommended in the current treatment guidelines for axial $\mathrm{SpA}{ }^{56,69}$. Only high dose (50 mg daily) of oral prednisone was effective in patients with $\mathrm{AS}^{75}$, and this approach might be considered as a short bridging therapy ${ }^{76}$. Local steroid injections are a valuable treatment option only in patients with peripheral SpA with oligoarthritis ( $\leq 4$ joints involved) ${ }^{76}$. Systemic corticosteroids can also be given in case of peripheral flare, but rapid tapering is required ${ }^{69}$.

\subsection{Immunomodulators}

Thiopurine therapy (azathioprine and 6-mercaptopurine) offers no advantage over placebo for induction of remission or clinical improvement in active $\mathrm{CD}$, although it allows patient to reduce steroid consumption ${ }^{77}$. In UC, thiopurines are efficacious in patients who flare when

steroids are withdrawn ${ }^{78,79}$. Furthermore, thiopurine therapy appears to be more effective than 
placebo for maintenance of remission in both $\mathrm{CD}^{80}$ and $\mathrm{UC}^{81}$. Also, the combination treatment of infliximab with azathioprine is more effective than infliximab monotherapy in $\mathrm{CD}^{82}$ and $\mathrm{UC}^{83}$. There is evidence, coming from a single large randomized trial, that intramuscular methotrexate provides a benefit for induction of remission and complete withdrawal from steroids in patients with refractory $\mathrm{CD}^{84}$. Also, intramuscular methotrexate is superior to placebo for maintenance of remission in $\mathrm{CD}^{85}$. Addition of methotrexate to infliximab therapy does not appear to provide an additional benefit over infliximab monotherapy in $\mathrm{CD}^{86}$. In $\mathrm{UC}$, parenteral methotrexate is not superior to placebo for induction of steroid-free remission, however it induces clinical remission without steroids in a significantly larger percentage of patients ${ }^{87}$. According to the ECCO guidelines, methotrexate can be considered in patients with steroid-dependent disease ${ }^{66}$. There is currently insufficient evidence to recommend methotrexate for the maintenance of remission in $\mathrm{UC}^{88}$. Treatment guidelines do not support the use of thiopurine therapy nor methotrexate in axial $\mathrm{SpA}^{56,69}$. Methotrexate did not show any benefit for axial manifestations in patients with active AS beyond the expected placebo response in a 16-week open-label trial ${ }^{89}$. Also, the combination of methotrexate with a TNF blocker for the treatment of axial $\mathrm{SpA}$ is not recommended given the lack of clear data ${ }^{76}$. Nevertheless, methotrexate is a well-proven therapeutic strategy in patients with psoriatic arthritis ${ }^{90}$ and RA ${ }^{91}$, and may therefore be considered in patients with peripheral $\mathrm{SpA}^{32,56,69,70}$.

\subsection{Anti-TNF therapy}

Numerous randomized controlled trials support the use of anti-TNF therapy in the treatment of $\mathrm{CD}$ and $\mathrm{UC}{ }^{92-95}$. Anti-TNF therapy remains the cornerstone in the treatment of IBD ${ }^{13}$. Infliximab and adalimumab are indicated in case of failure of corticosteroids and/or immunosuppressants in both CD and UC. Certoluzimab pegol is only labelled for the use in 
$\mathrm{CD}$, and golimumab is only labelled for the use in $\mathrm{UC}^{36,66}$. Both infliximab and adalimumab can be used in the case of complex fistulising perianal disease, in conjunction with surgical drainage, but the level of evidence is lower for adalimumab compared to infliximab ${ }^{96-99}$. Infliximab, adalimulab, golimumab and certolizumab pegol have approval, both in the EU and in the USA, for the use in patients with AS (r-axSpA), as multiple treatment trials showed improvement in clinical symptoms, CRP levels and MRI-detectable inflammation in the sacroiliac joints and spine in these patients ${ }^{27,76}$. Adalimumab, golimumab and certolizumab pegol, but not infliximab, seem to be equally effective in patients with nr-axSpA as in patients with $\mathrm{r}-\mathrm{axSpA}{ }^{100}$. All 3 agents already have additional approval for the use in nr-axSpA in the EU, but not yet in the USA. TNF blockers should be initiated in patients with active axial SpA who are refractory to NSAIDs and with at least one of the following: sacroiliitis on x-ray for $\mathrm{r}-\mathrm{axSpA}$, and inflammatory sacroiliitis on MRI and/or elevated CRP levels for $\mathrm{nr}$-axSpA $56,69,76$. Etanercept, another anti-TNF agent, has proven efficacy in the treatment of axial SpA ${ }^{100}$, but not in IBD. Concerning peripheral arthritis, anti-TNF agents have demonstrated efficacy in psoriatic arthritis (adalimumab, certolizumab, etanercept) ${ }^{101}$ and adalimumab also showed promising results in two placebo-controlled trials in patients with peripheral SpA 102,103. Furthermore, the CARE study, a large European open-label trial, showed resolution of EIMs exceeding 50\% in CD patients treated with adalimumab, including peripheral arthritis and r-axSpA 104 .

\subsection{Vedolizumab}

Vedolizumab is a gut-selective $\alpha 4 \beta 7$ integrin antagonist, modulating gut lymphocyte trafficking. Vedoluzimab is more effective than placebo as induction and maintenance therapy for $\mathrm{CD}^{105}$ and $\mathrm{UC}^{106}$. 
Although an exclusively local effect of vedolizumab could be expected based on the restricted presence of the $\alpha 4 \beta 7$ ligand, namely mucosal vascular addressin cell adhesion molecule 1 (madcam-1), in vascular and lymphatic vessels of the gut ${ }^{107,108}$, previous demonstration of $\alpha 4 \beta 7$ integrin in the joint ${ }^{109}$ led to the expectation of a therapeutic efficacy in SpA. In contrast, vedolizumab induced arthritis flare and/or sacroiliitis in a recent small case-series of 5 IBD patients treated with the drug ${ }^{110}$. Nevertheless, arthritis is often driven by intestinal inflammation and in a recent study in IBD patients who were initated with vedolizumab a complete remission of pre-existing arthropathies was noticed in 24/46 (52.2\%) patients ${ }^{111}$. Also, in a post-hoc analysis of the GEMINI-2 cohort, there was a trend for reduced incidence of new or worsening arthralgia and arthritis and increased rates of sustained resolution of arthralgia and arthritis in patients receiving vedolizumab ${ }^{112}$. Orlando et al initiated vedolizumab in 22 IBD patients with associated SpA. No patient experienced a flare-up of the rheumatic disease and in 6 out of 14 patients (46.2\%) with active SpA at the time of induction with vedolizumab, a sharp clinical benefit of the SpA was noticed ${ }^{113}$. Altogether, there is a need for large cohort studies exploring the potential benefit of vedolizumab on IBDassociated SpA.

\subsection{Ustekinumab}

Ustekinumab is a monoclonal antibody that binds to the p40 subunit common to interleukin12 and interleukin-23 and prevents their binding to IL-12R $\beta 1$ expressed on the surface of immune cells. Patients with moderately to severely active CD that received intravenous ustekinumab had a significantly higher rate of response than those receiving placebo. Subcutaneous ustekinumab maintained remission in patients who had a clinical response to induction therapy ${ }^{14}$. A study to evaluate the safety and efficacy of ustekinumab induction and maintenance therapy in moderately to severely active UC is ongoing ${ }^{114}$. 
Ustekinumab has demonstrated its efficacy in psoriatic arthritis ${ }^{15}$ and induced a reduction of signs and symptoms in a prospective, open-label, proof-of-concept clinical trial in patients with active $\mathrm{AS}^{115}$. Nevertheless, the use of ustekinumab in axial $\mathrm{SpA}$ is not yet firmly demonstrated and final results of phase 3 trials in r-axSpA ${ }^{116}$ and nr-axSpA ${ }^{117}$ need to be awaited.

\subsection{Janus kinase (JAK) inhibitors}

Tofacitinib is an orally active small chemical molecule, targeting all JAKs (JAK1/JAK2/JAK3/TYK2), but preferentially JAK1 and JAK3 ${ }^{118,119}$. Tofacitinib is not effective in $\mathrm{CD}^{120,121}$, but results from the phase 3 OCTAVE trials showed superiority of tofacitinib over placebo as induction and maintenance therapy in patients with moderately-tosevere active $\mathrm{UC}^{122}$. Filgotinib is a selective JAK1 inhibitor that induces clinical remission in significantly more patients with active CD compared to placebo ${ }^{123}$, but these promising results need to be confirmed in phase 3 trials. Also upadacitinib, another selective JAK1 inhibitor, demonstrated endoscopic improval and clinical benefit as induction therapy in a recent dose-ranging study in 220 patients with moderate to severe refractory $\mathrm{CD}^{124}$. Further clinical data are necessary to assess the potential of selective JAK 1 inhibition in UC ${ }^{125}$. In a recent phase 2 study in patients with active AS, tofacitinib $5 \mathrm{mg}$ and $10 \mathrm{mg}$ twice daily demonstrated greater clinical efficacy versus placebo in reducing signs, symptoms and objective endpoints after 12 weeks of treatment ${ }^{126}$. There are no data available on the use of selective JAK1 inhibitors in SpA.

\section{Treatment guidelines in patients with IBD and $\operatorname{SpA}$}

An Italian expert panel developed therapeutic algorithms in patients with IBD and SpA depending on the disease activity of both entities ${ }^{5}$. Based on these principles, also a very 
recent a Delphi consensus summarizes strategies for the best management of patients with coexisting IBD and $\mathrm{SpA}^{127}$. The first ECCO consensus on EIMs in IBD provides a limited set of statements concerning the treatment of peripheral and axial SpA in IBD patients ${ }^{3}$. The current available treatment guidelines in IBD patients with SpA are summarized in table 4. The jointly management of IBD patients with SpA by the gastroenterologist and the rheumatologist is generally supported. The choice of a pharmacologic treatment depends on the dominant disease. Steroids and 5-aminosalicylates should only be used when indicated for IBD, but not for SpA. Sulfasalazine and methotrexate may have a role in the treatment of concomitant (mainly peripheral) SpA. Anti-TNF blockers have to be started according to the treatment guideline of the dominant disease. NSAIDs for SpA can only be considered in patients without active IBD and should be limited to short periods in time.

\section{Summary}

SpA is the most common EIM in IBD and occurs in up to $13 \%$ of patients. On the other hand, microscopic intestinal inflammation is documented in approximately $50 \%$ of patients with SpA. SpA is classified according to the ASAS criteria, distinguishing peripheral from axial involvement. Timely diagnosis of both SpA in IBD patients and IBD in SpA patients is important. Cooperation between the gastroenterologist and the rheumatologist is necessary to guarantee an integrated management that provides the best possible care to IBD patients with SpA. Whether treat-to-target strategies will prevent long-term outcomes such as disability and organ damage is yet to be established in both IBD and SpA. Current treatment guidelines in patients with IBD and SpA are developed by an Italian expert panel (2014) and by ECCO (2016). Given its well-documented efficacy in both diseases, anti-TNF therapy remains the cornerstone in the treatment when IBD and SpA coexist. Whether drugs with a gut-specific 
mode of action, such as vedolizumab, work for IBD-related arthritis is still debated. NSAIDs use for SpA can only be considered in patients without active IBD and should be limited to short periods in time.

\section{Expert commentary}

The coexistence of IBD and SpA generates challenges as well as opportunities for both the gastroenterologist and the rheumatologist.

Although concomitant IBD and $\mathrm{SpA}$ is frequent, awareness in health care practitioners remains low and too often a well-structured multidisciplinary management is not offered to the patient. Therefore, regular deliberation between the gastroenterologist and the rheumatologist, for example in a monthly multidisciplinary team meeting, can optimise care by giving the opportunity to discuss complex cases and make jointly treatment decisions. Joint complaints in IBD patients are often difficult to deal with and a broad differential diagnosis exists. Mainly arthralgia (joint pain without inflammation) and arthritis (joint pain with objective signs of inflammation) need to be distinguished. Arthralgia in IBD patients can be caused by the introduction of thiopurines ${ }^{128,129}$ or by the withdrawal of corticosteroids ${ }^{130}$. It is also a common side effect in patients treated with anti-TNF therapy ${ }^{131,132}$. Furthermore, corticosteroid-related osteonecrosis and infliximab-related lupus-like syndrome can mimic SpA in IBD patients ${ }^{133,134}$. Given the important repercussions of a correct diagnosis for the treatment strategy, IBD patients who develop joint pain deserve a thoroughly assessment by a rheumatologist. On the other hand, gastrointestinal complaints in SpA patients are not always caused by IBD. Other entities such as irritable bowel syndrome, coeliac disease, lactose ingestion, gastrointestinal infection, bacterial overgrowth, bile salt diarrhea, ischemia or 
vasculitis are part of the differential diagnosis. An expert advice by a gastroenterologist to choose the most appropriate diagnostic strategy is warranted.

Practitioners need to be aware that management options for SpA can influence the IBD disease course in a negative way. NSAIDs are a first-line treatment option for SpA but increase the risk of IBD relapse ${ }^{135,136}$. Some data suggest that the use of COX-2 inhibitors may be safer than conventional NSAIDs ${ }^{137,138}$, but this needs to be confirmed. We support the general idea that the use of NSAIDs in IBD patients should be avoided when possible, although short-term use is acceptable when necessary ${ }^{139}$. Etanercept, an anti-TNF agent with proved efficacy in the treatment of axial $\mathrm{SpA}^{100}$ can induce IBD ${ }^{140,141}$. Its use should not be recommended in first line of treatment of SpA in patients with concomitant IBD.

Nevertheless, it may be considered in patients with active SpA who fail all other TNF agents and have no flare of their IBD.

Treatment targets in IBD and SpA are similar and include the early intervention in the disease course by tight control of the inflammation to prevent structural damage. To further optimise these goals, new prospective disease-modifying trials are eagerly needed in both diseases. The well-established advantage of anti-TNF therapy in patients with EIMs ${ }^{142}$ illustrates the possibility to treat two diseases with one management option. In this regard, the potential of drugs with a gut-specific mode of action in the treatment of IBD-related arthritis warrants further exploration, since arthritis is often driven by intestinal inflammation. The efficacy of ustekinumab in $\mathrm{CD}^{14}$ and tofacitinib in $\mathrm{UC}^{122}$ is recently confirmed, but their potential to simultaneously treat SpA needs further evaluation.

\section{Five-year view}


To develop better treatment strategies for patients with concomitant IBD and SpA, we need a more profound understanding of the underlying disease mechanisms that play in these patients. Research will focus around two major topics in the upcoming years: the role of drugs with a gut-specific mode of action in the treatment of concomitant rheumatic disease and the role of gut microbiota in the pathogenesis of IBD and SpA.

Real-life experience of the use of vedolizumab and more prospectively collected data in large cohort studies will clarify the effect of the drug in the treatment of IBD-related arthritis. We belief that vedolizumab will more likely have a beneficial, rather than a paradoxical, effect in patients with concomitant IBD and SpA. Several recent clinical data support this expectation 111-113. The upregulation of mucosal vascular cell adhesion molecule 1 in the high endothelial venules of bone marrow in patients with active axial SpA ${ }^{143}$ could (partially) explain this effect.

Growing insight into the composition and functionality of the mucosal microbiota has revealed its involvement in mucosal barrier integrity and immune function. The association between compositional and metabolic changes in the intestinal microbiota (dysbiosis) and IBD is now widely accepted. Gut microbiota also shapes local and systemic immune responses, and therefor can potentially affect the development and progression of rheumatic diseases ${ }^{144}$. Further basic and translational research will elaborate the exact mechanisms that play a part in this interaction, and this can hopefully lead to new therapeutic strategies for patients with concomitant IBD and SpA. 


\section{Key issues}

1. The most common extra-intestinal manifestation in patients with inflammatory bowel disease (IBD) is spondyloarthritis (SpA). Microscopic intestinal inflammation is documented in almost $50 \%$ of the patients with SpA.

- An integrated management of patients with coexisting IBD and SpA is necessary to guarantee the timely diagnosis of both entities, and to provide the best possible care to patients.

2. Current treatment guidelines in patients with IBD and SpA are developed by an Italian expert panel (2014). Also the European Crohn's and Colitis Organisation (ECCO) (2016)) consensus describes a diagnostic approach for arthritis in IBD patients.

3. Anti-TNF therapy remains the cornerstone in the treatment of patients with coexisting IBD and SpA.

4. NSAIDs for SpA can only be considered in patients without active IBD and should be limited to short periods in time.

5. The potential of drugs with a gut-specific mode of action in the treatment of IBDrelated arthritis warrants further exploration. 


\section{Funding}

This paper was not funded.

\section{Declaration of Interest}

L Peyrin-Biroulet received honoraria from Merck, Abbvie, Janssen, Genentech, Mitsubishi, Ferring, Norgine, Tillots, Vifor, Hospira/Pfizer, Celltrion, Takeda, Biogaran, Boerhinger-Ingelheim, Lilly, HAC-Pharma, Index Pharmaceuticals, Amgen, Sandoz, Forward Pharma GmbH, Celgene, Biogen, Lycera, Samsung Bioepis. P Bossuyt received educational grants from AbbVie, speaker fees from AbbVie, Takeda, Vifor Pharma and advisory board fees from Hospira, Janssen, MSD, Mundipharma, Roche, Pfizer, Takeda, Dr Falk Benelux. S Danese has served as a speaker, a consultant and an advisory board member for Abbvie, Ferring, Hospira, Johnson \& Johnson, Merck, Millennium Takeda, Mundipharma, Pfizer, Tigenix, UCB Pharma and Vifor. D Loeuille received educational grants from Abbvie, Pfizer, speaker from Abbvie, UCB, Pfizer, MSD, Jansen, Novartis. The authors have no other relevant affiliations or financial involvement with any organization or entity with a financial interest in or financial conflict with the subject matter or materials discussed in the manuscript apart from those disclosed. Peer reviewers on this manuscript have no relevant financial or other relationships to disclose.

\section{References}

Papers of special note have been highlighted as:

* of interest

** of considerable interest

1. Torres J, Mehandru S, Colombel J-F, et al. Crohn's disease. Lancet 2017;389:17411755. 
2. Ungaro R, Mehandru S, Allen PB, et al. Ulcerative colitis. Lancet 2017;389:17561770.

3. Harbord M, Annese V, Vavricka SR, et al. The First European Evidence-based Consensus on Extra-intestinal Manifestations in Inflammatory Bowel Disease. J Crohn's Colitis 2016;10:239-254.

4. Gionchetti P, Rizzello F. IBD: IBD and spondyloarthritis: joint management. Nat Rev Gastroenterol Hepatol 2016;13:9-10.

5. Olivieri I, Cantini F, Castiglione F, et al. Italian Expert Panel on the management of patients with coexisting spondyloarthritis and inflammatory bowel disease. Autoimmun Rev 2014;13:822-30.

6. Boonen A, Linden SM van der. The burden of ankylosing spondylitis. J Rheumatol Suppl 2006;78:4-11.

7. Michelsen B, Fiane R, Diamantopoulos AP, et al. A Comparison of Disease Burden in Rheumatoid Arthritis, Psoriatic Arthritis and Axial Spondyloarthritis. PLoS One 2015;10(4):e0123582.

8. Santiago MG, Marques A, Kool M, et al. Invalidation in Patients with Rheumatic Diseases: Clinical and Psychological Framework. J Rheumatol 2017:jrheum.160559.

9. Sieper J, Hu X, Black CM, et al. Systematic review of clinical, humanistic, and economic outcome comparisons between radiographic and non-radiographic axial spondyloarthritis. Semin Arthritis Rheum 2017;46:746-753.

10. Praet L Van, Bosch FE Van den, Jacques P, et al. Microscopic gut inflammation in axial spondyloarthritis: a multiparametric predictive model. Ann Rheum Dis $2013 ; 72: 414-7$.

11. Vos M De, Mielants H, Cuvelier C, et al. Long-term evolution of gut inflammation in patients with spondyloarthropathy. Gastroenterology 1996;110:1696-703. 
12. Palazzi C, D’Angelo S, Gilio M, et al. Pharmacological therapy of spondyloarthritis. Expert Opin Pharmacother 2015;16:1495-1504.

13. Pouillon L, Bossuyt P, Peyrin-Biroulet L. Considerations, challenges and future of antiTNF therapy in treating inflammatory bowel disease. Expert Opin Biol Ther 2016;16:1277-1290.

14. Feagan BG, Sandborn WJ, Gasink C, et al. Ustekinumab as Induction and Maintenance Therapy for Crohn's Disease. N Engl J Med 2016;375:1946-1960.

15. Kavanaugh A, Puig L, Gottlieb AB, et al. Efficacy and safety of ustekinumab in psoriatic arthritis patients with peripheral arthritis and physician-reported spondylitis: post-hoc analyses from two phase III, multicentre, double-blind, placebo-controlled studies (PSUMMIT-1/PSUMMIT-2). Ann Rheum Dis 2016;75:1984-1988.

16. Karreman MC, Luime JJ, Hazes JMW, et al. The Prevalence and Incidence of Axial and Peripheral Spondyloarthritis in Inflammatory Bowel Disease: A Systematic Review and Meta-analysis. J Crohn's Colitis 2016;11:631-642.

17. Vlam K de, Mielants H, Cuvelier C, et al. Spondyloarthropathy is underestimated in inflammatory bowel disease: prevalence and HLA association. J Rheumatol 2000;27:2860-5.

18. Peeters H, Cruyssen B Vander, Mielants H, et al. Clinical and genetic factors associated with sacroiliitis in Crohn's disease. J Gastroenterol Hepatol 2007;23(1):132-7.

19. Queiro R, Maiz O, Intxausti J, et al. Subclinical sacroiliitis in inflammatory bowel disease: a clinical and follow-up study. Clin Rheumatol 2000;19:445-9.

20. Conigliaro P, Chimenti MS, Ascolani M, et al. Impact of a multidisciplinary approach in enteropathic spondyloarthritis patients. Autoimmun Rev 2016;15:184-190.

21. Rovisco J, Duarte C, Batticcioto A, et al. Hidden musculoskeletal involvement in 
inflammatory bowel disease: a multicenter ultrasound study. BMC Musculoskelet Disord 2016;17:84.

22. Rudwaleit M, Heijde D van der, Landewe R, et al. The Assessment of SpondyloArthritis international Society classification criteria for peripheral spondyloarthritis and for spondyloarthritis in general. Ann Rheum Dis 2011;70:25-31.

23. Rudwaleit M, Heijde D van der, Landewé R, et al. The development of Assessment of SpondyloArthritis international Society classification criteria for axial spondyloarthritis (part II): validation and final selection. Ann Rheum Dis 2009;68:777-83.

24. Sepriano A, Landew R, Heijde D van der, et al. Predictive validity of the ASAS classification criteria for axial and peripheral spondyloarthritis after follow-up in the ASAS cohort: a final analysis. Ann Rheum Dis 2016;75:1034-1042.

25. Salvarani C, Fries W. Clinical features and epidemiology of spondyloarthritides associated with inflammatory bowel disease. World J Gastroenterol 2009;15:2449-55.

26. Mandl P, Navarro-Compán V, Terslev L, et al. EULAR recommendations for the use of imaging in the diagnosis and management of spondyloarthritis in clinical practice. Ann Rheum Dis 2015;74:1327-1339.

27. Taurog JD, Chhabra A, Colbert RA. Ankylosing Spondylitis and Axial Spondyloarthritis. N Engl J Med 2016;374:2563-2574.

28. Leclerc-Jacob S, Lux G, Rat AC, et al. The prevalence of inflammatory sacroiliitis assessed on magnetic resonance imaging of inflammatory bowel disease: a retrospective study performed on 186 patients. Aliment Pharmacol Ther 2014;39:95762.

29. Lambert RGW, Bakker PAC, Heijde D van der, et al. Defining active sacroiliitis on MRI for classification of axial spondyloarthritis: update by the ASAS MRI working group. Ann Rheum Dis 2016;75:1958-1963. 
30. Steer S, Jones H, Hibbert J, et al. Low back pain, sacroiliitis, and the relationship with HLA-B27 in Crohn's disease. J Rheumatol 2003;30:518-22.

31. Orchard TR, Holt H, Bradbury L, et al. The prevalence, clinical features and association of HLA-B27 in sacroiliitis associated with established Crohn's disease. Aliment Pharmacol Ther 2009;29:193-7.

32. Arvikar SL, Fisher MC. Inflammatory bowel disease associated arthropathy. Curr Rev Musculoskelet Med 2011;4:123-31.

33. Stolwijk C, Pierik M, Landewé R, et al. Prevalence of self-reported spondyloarthritis features in a cohort of patients with inflammatory bowel disease. Can J Gastroenterol 2013;27:199-205.

34. Ibn Yacoub Y, Amine B, Laatiris A, et al. Relationship between diagnosis delay and disease features in Moroccan patients with ankylosing spondylitis. Rheumatol Int 2012;32:357-360.

35. Subramaniam K, Tymms K, Shadbolt B, et al. Spondyloarthropathy in inflammatory bowel disease patients on TNF inhibitors. Intern Med J 2015;45:1154-1160.

36. Gomollon F, Dignass A, Annese V, et al. 3rd European Evidence-based Consensus on the Diagnosis and Management of Crohn's Disease 2016: Part 1: Diagnosis and Medical Management. J Crohn's Colitis 2017;11:3-25.

37. Magro F, Gionchetti P, Eliakim R, et al. Third European Evidence-based Consensus on Diagnosis and Management of Ulcerative Colitis. Part 1: Definitions, Diagnosis, Extraintestinal Manifestations, Pregnancy, Cancer Surveillance, Surgery, and Ileo-anal Pouch Disorders for the European Crohn's and. J Crohn's Colitis 2017;11:649-670.

38. Praet L Van, Jans L, Carron P, et al. Degree of bone marrow oedema in sacroiliac joints of patients with axial spondyloarthritis is linked to gut inflammation and male sex: results from the GIANT cohort. Ann Rheum Dis 2014;73:1186-9. 
39. Peyrin-Biroulet L, Billioud V, D'Haens G, et al. Development of the Paris definition of early Crohn's disease for disease-modification trials: results of an international expert opinion process. Am J Gastroenterol 2012;107:1770-6.

40. Cypers H, Varkas G, Beeckman S, et al. Elevated calprotectin levels reveal bowel inflammation in spondyloarthritis. Ann Rheum Dis 2016;75:1357-1362.

41. Peyrin-Biroulet L, Sandborn W, Sands BE, et al. Selecting Therapeutic Targets in Inflammatory Bowel Disease (STRIDE): Determining Therapeutic Goals for Treat-toTarget. Am J Gastroenterol 2015;110:1324-38.

42. Baert F, Moortgat L, Assche G Van, et al. Mucosal healing predicts sustained clinical remission in patients with early-stage Crohn's disease. Gastroenterology 2010;138:463-8; quiz e10-1.

43. Colombel J-F, Rutgeerts PJ, Sandborn WJ, et al. Adalimumab induces deep remission in patients with Crohn's disease. Clin Gastroenterol Hepatol 2014;12:414-22.e5.

44. Colombel JF, Rutgeerts P, Reinisch W, et al. Early Mucosal Healing With Infliximab Is Associated With Improved Long-term Clinical Outcomes in Ulcerative Colitis. Gastroenterology 2011;141:1194-1201.

45. Laharie D, Filippi J, Roblin X, et al. Impact of mucosal healing on long-term outcomes in ulcerative colitis treated with infliximab: a multicenter experience. Aliment Pharmacol Ther 2013;37:998-1004.

46. Miyoshi J, Matsuoka K, Inoue N, et al. Mucosal healing with oral tacrolimus is associated with favorable medium- and long-term prognosis in steroidrefractory/dependent ulcerative colitis patients. J Crohn's Colitis 2013;7:e609-e614.

47. Ardizzone S, Cassinotti A, Duca P, et al. Mucosal Healing Predicts Late Outcomes After the First Course of Corticosteroids for Newly Diagnosed Ulcerative Colitis. Clin Gastroenterol Hepatol 2011;9:483-489.e3. 
48. Allen PB, Olivera P, Emery P, et al. Review article: moving towards common therapeutic goals in Crohn's disease and rheumatoid arthritis. Aliment Pharmacol Ther 2017;45:1058-1072.

49. Vuitton L, Peyrin-Biroulet L, Colombel JF, et al. Defining endoscopic response and remission in ulcerative colitis clinical trials: an international consensus. Aliment Pharmacol Ther 2017;45:801-813.

50. Vuitton L, Marteau P, Sandborn WJ, et al. IOIBD technical review on endoscopic indices for Crohn's disease clinical trials. Gut 2016;65:1447-55.

51. Colombel JF, Panaccione R, Bossuyt P, et al. Superior Endoscopic and Deep Remission Outcomes in Adults with Moderate to Severe Crohn's Disease Managed with Treat to Target Approach Versus Clinical Symptoms: Data from Calm. Gastroenterology 2017;152:S155.

52. Osterman MT, Aberra FN, Cross R, et al. Mesalamine Dose Escalation Reduces Fecal Calprotectin in Patients With Quiescent Ulcerative Colitis. Clin Gastroenterol Hepatol 2014;12:1887-1893.e3.

53. Schipper LG, Vermeer $\mathrm{M}$, Kuper HH, et al. A tight control treatment strategy aiming for remission in early rheumatoid arthritis is more effective than usual care treatment in daily clinical practice: a study of two cohorts in the Dutch Rheumatoid Arthritis Monitoring registry. Ann Rheum Dis 2012;71:845-50.

54. Pope JE, Haraoui B, Rampakakis E, et al. Treating to a target in established active rheumatoid arthritis patients receiving a tumor necrosis factor inhibitor: results from a real-world cluster-randomized adalimumab trial. Arthritis Care Res (Hoboken) 2013;65:1401-9.

55. Cheng J, Wei -Chung. Treat-to-Target in Spondyloarthritis: Implications for Clinical Trial Designs. Drugs 2014;74(10):1091-6. 
56. Heijde D van der, Ramiro S, Landewé R, et al. 2016 update of the ASAS-EULAR management recommendations for axial spondyloarthritis. Ann Rheum Dis 2017;76:978-991.

57. Poddubnyy D, Protopopov M, Haibel H, et al. High disease activity according to the Ankylosing Spondylitis Disease Activity Score is associated with accelerated radiographic spinal progression in patients with early axial spondyloarthritis: results from the GErman SPondyloarthritis Inception Cohort. Ann Rheum Dis 2016;75:21142118.

58. Baraliakos X, Braun J. Anti-TNF-alpha therapy with infliximab in spondyloarthritides. Expert Rev Clin Immunol 2010;6:9-19.

59. Smolen JS, Braun J, Dougados M, et al. Treating spondyloarthritis, including ankylosing spondylitis and psoriatic arthritis, to target: recommendations of an international task force. Ann Rheum Dis 2014;73:6-16.

60. Baeten D, Sieper J, Braun J, et al. Secukinumab, an Interleukin-17A Inhibitor, in Ankylosing Spondylitis. N Engl J Med 2015;373:2534-2548.

61. Ford AC, Kane S V, Khan KJ, et al. Efficacy of 5-aminosalicylates in Crohn's disease: systematic review and meta-analysis. Am J Gastroenterol 2011;106:617-29.

62. Lim W-C, Wang Y, MacDonald JK, et al. Aminosalicylates for induction of remission or response in Crohn's disease. Cochrane Database Syst Rev 2016;7:CD008870.

63. Ford AC, Achkar J-P, Khan KJ, et al. Efficacy of 5-Aminosalicylates in Ulcerative Colitis: Systematic Review and Meta-Analysis. Am J Gastroenterol 2011;106:601-616.

64. Wang Y, Parker CE, Bhanji T, et al. Oral 5-aminosalicylic acid for induction of remission in ulcerative colitis. Cochrane Database Syst Rev 2016;4:CD000543.

65. Wang Y, Parker CE, Feagan BG, et al. Oral 5-aminosalicylic acid for maintenance of remission in ulcerative colitis. Cochrane Database Syst Rev 2016;5:CD000544. 
66. Harbord M, Eliakim R, Bettenworth D, et al. Third European Evidence-based Consensus on Diagnosis and Management of Ulcerative Colitis. Part 2: Current Management. J Crohn's Colitis 2017:1-24. DOI: 10.1093/ecco-jcc/jjx009

67. Braun J, Zochling J, Baraliakos X, et al. Efficacy of sulfasalazine in patients with inflammatory back pain due to undifferentiated spondyloarthritis and early ankylosing spondylitis: a multicentre randomised controlled trial. Ann Rheum Dis 2006;65:114753.

68. Chen J, Lin S, Liu C. Sulfasalazine for ankylosing spondylitis. Cochrane Database Syst Rev 2014;11:CD004800.

••69. Ward MM, Deodhar A, Akl EA, et al. American College of Rheumatology/Spondylitis Association of America/Spondyloarthritis Research and Treatment Network 2015 Recommendations for the Treatment of Ankylosing Spondylitis and Nonradiographic Axial Spondyloarthritis. Arthritis Rheumatol 2016;68:282-98.

American college of Rheumatology/Spondylitis Association of America/Spondyloarthrithis Research and treatment network recommendations for the treatment of r-axSpA and nr-axSpA.

70. Mallinson C, Thorne P, Rahman DD, et al. 2014 Update of the Canadian Rheumatology Association/Spondyloarthritis Research Consortium of Canada Treatment Recommendations for the Management of Spondyloarthritis. Part II: Specific Management Recommendations. J Rheumatol 2015;4242:665-681.

71. Summers RW, Switz DM, Sessions JT, et al. National Cooperative Crohn's Disease Study: results of drug treatment. Gastroenterology 1979;77:847-69.

72. Malchow H, Ewe K, Brandes JW, et al. European Cooperative Crohn's Disease Study (ECCDS): results of drug treatment. Gastroenterology 1984;86:249-66.

73. Sandborn WJ, Bosworth B, Zakko S, et al. Budesonide Foam Induces Remission in 
Patients With Mild to Moderate Ulcerative Proctitis and Ulcerative Proctosigmoiditis. Gastroenterology 2015;148:740-750.e2.

74. Turner D, Walsh CM, Steinhart AH, et al. Response to corticosteroids in severe ulcerative colitis: a systematic review of the literature and a meta-regression. Clin Gastroenterol Hepatol 2007;5:103-10.

75. Haibel H, Fendler C, Listing J, et al. Efficacy of oral prednisolone in active ankylosing spondylitis: results of a double-blind, randomised, placebo-controlled short-term trial. Ann Rheum Dis 2014;73:243-6.

-76. Sieper J, Poddubnyy D. New evidence on the management of spondyloarthritis. Nat Rev Rheumatol 2016;12:282-95.

\section{Review summarizing the new evidence on the management of SpA.}

77. Chande N, Townsend CM, Parker CE, et al. Azathioprine or 6-mercaptopurine for induction of remission in Crohn's disease. Cochrane Database Syst Rev 2016;10:CD000545.

78. Ardizzone S, Maconi G, Russo A, et al. Randomised controlled trial of azathioprine and 5-aminosalicylic acid for treatment of steroid dependent ulcerative colitis. Gut 2006;55:47-53.

79. Chebli LA, Chaves LD de M, Pimentel FF, et al. Azathioprine maintains long-term steroid-free remission through 3 years in patients with steroid-dependent ulcerative colitis. Inflamm Bowel Dis 2010;16:613-9.

80. Chande N, Patton PH, Tsoulis DJ, et al. Azathioprine or 6-mercaptopurine for maintenance of remission in Crohn's disease. Cochrane Database Syst Rev 2015;10:CD000067.

81. Timmer A, Patton PH, Chande N, et al. Azathioprine and 6-mercaptopurine for maintenance of remission in ulcerative colitis. Cochrane Database Syst Rev 
2016;5:CD000478.

82. Colombel JF, Sandborn WJ, Reinisch W, et al. Infliximab, azathioprine, or combination therapy for Crohn's disease. N Engl J Med 2010;362:1383-95.

83. Panaccione R, Ghosh S, Middleton S, et al. Combination therapy with infliximab and azathioprine is superior to monotherapy with either agent in ulcerative colitis. Gastroenterology 2014;146:392-400.e3.

84. Feagan BG, Rochon J, Fedorak RN, et al. Methotrexate for the treatment of Crohn's disease. The North American Crohn's Study Group Investigators. N Engl J Med $1995 ; 332: 292-7$.

85. McDonald JW, Wang Y, Tsoulis DJ, et al. Methotrexate for induction of remission in refractory Crohn's disease. Cochrane Database Syst Rev 2014;8:CD003459.

86. Feagan BG, McDonald JWD, Panaccione R, et al. Methotrexate in combination with infliximab is no more effective than infliximab alone in patients with Crohn's disease. Gastroenterology 2014;146:681-688.e1.

87. Carbonnel F, Colombel JF, Filippi J, et al. Methotrexate Is Not Superior to Placebo for Inducing Steroid-Free Remission, but Induces Steroid-Free Clinical Remission in a Larger Proportion of Patients With Ulcerative Colitis. Gastroenterology 2016;150:380388.e4.

88. Wang Y, MacDonald JK, Vandermeer B, et al. Methotrexate for maintenance of remission in ulcerative colitis. Cochrane Database Syst Rev 2015;8:CD007560.

89. Haibel H, Brandt HC, Song IH, et al. No efficacy of subcutaneous methotrexate in active ankylosing spondylitis: a 16-week open-label trial. Ann Rheum Dis 2007;66:419-21.

90. Ash Z, Gaujoux-Viala C, Gossec L, et al. A systematic literature review of drug therapies for the treatment of psoriatic arthritis: current evidence and meta-analysis 
informing the EULAR recommendations for the management of psoriatic arthritis. Ann Rheum Dis 2012;71:319-26.

91. Hazlewood GS, Barnabe C, Tomlinson G, et al. Methotrexate monotherapy and methotrexate combination therapy with traditional and biologic disease modifying antirheumatic drugs for rheumatoid arthritis: A network meta-analysis. Cochrane Database Syst Rev 2016;8:CD010227.

92. Singh S, Garg SK, Pardi DS, et al. Comparative efficacy of biologic therapy in biologic-naïve patients with Crohn disease: a systematic review and network metaanalysis. Mayo Clin Proc 2014;89:1621-35.

93. Stidham RW, Lee TCH, Higgins PDR, et al. Systematic review with network metaanalysis: the efficacy of anti-TNF agents for the treatment of Crohn's disease. Aliment Pharmacol Ther 2014;39:1349-62.

94. Hazlewood GS, Rezaie A, Borman M, et al. Comparative effectiveness of immunosuppressants and biologics for inducing and maintaining remission in Crohn's disease: A network meta-analysis. Gastroenterology 2015;148:344-54.e5; quiz e14-5.

95. Danese S, Fiorino G, Peyrin-Biroulet L, et al. Biological agents for moderately to severely active ulcerative colitis: a systematic review and network meta-analysis. Ann Intern Med 2014;160:704-11.

96. Present DH, Rutgeerts P, Targan S, et al. Infliximab for the treatment of fistulas in patients with Crohn's disease. N Engl J Med 1999;340:1398-405.

97. Sands BE, Anderson FH, Bernstein CN, et al. Infliximab maintenance therapy for fistulizing Crohn's disease. N Engl J Med 2004;350:876-85.

98. Colombel J-F, Schwartz DA, Sandborn WJ, et al. Adalimumab for the treatment of fistulas in patients with Crohn's disease. Gut 2009;58:940-8.

99. Dewint P, Hansen BE, Verhey E, et al. Adalimumab combined with ciprofloxacin is 
superior to adalimumab monotherapy in perianal fistula closure in Crohn's disease: a randomised, double-blind, placebo controlled trial (ADAFI). Gut 2014;63:292-9.

100. Callhoff J, Sieper J, Weiß A, et al. Efficacy of TNF $\alpha$ blockers in patients with ankylosing spondylitis and non-radiographic axial spondyloarthritis: a meta-analysis. Ann Rheum Dis 2015;74:1241-8.

101. Huynh D, Kavanaugh A. Psoriatic arthritis: current therapy and future directions. Expert Opin Pharmacother 2013;14:1755-64.

102. Paramarta JE, Rycke L De, Heijda TF, et al. Efficacy and safety of adalimumab for the treatment of peripheral arthritis in spondyloarthritis patients without ankylosing spondylitis or psoriatic arthritis. Ann Rheum Dis 2013;72:1793-9.

103. Mease P, Sieper J, Bosch F Van den, et al. Randomized controlled trial of adalimumab in patients with nonpsoriatic peripheral spondyloarthritis. Arthritis Rheumatol $2015 ; 67: 914-23$.

104. Löfberg R, Louis E V, Reinisch W, et al. Adalimumab produces clinical remission and reduces extraintestinal manifestations in Crohn's disease: results from CARE. Inflamm Bowel Dis 2012;18:1-9.

105. Sandborn WJ, Feagan BG, Rutgeerts P, et al. Vedolizumab as induction and maintenance therapy for Crohn's disease. N Engl J Med 2013;369:711-21.

-106. Feagan BG, Rutgeerts P, Sands BE, et al. Vedolizumab as induction and maintenance therapy for ulcerative colitis. N Engl J Med 2013;369:699-710.

\section{Pivotal trial providing evidence for the use of ustekinumab in CD.}

107. Schweighoffer T, Tanaka Y, Tidswell M, et al. Selective expression of integrin alpha 4 beta 7 on a subset of human CD4+ memory T cells with Hallmarks of gut-trophism. $\mathbf{J}$ Immunol 1993;151:717-29.

108. Wyant T, Leach T, Sankoh S, et al. Vedolizumab affects antibody responses to 
immunisation selectively in the gastrointestinal tract: randomised controlled trial results. Gut 2015;64:77-83.

109. Elewaut D, Keyser F De, Van Den Bosch F, et al. Enrichment of T cells carrying beta7 integrins in inflamed synovial tissue from patients with early spondyloarthropathy, compared to rheumatoid arthritis. J Rheumatol 1998;25:1932-7.

110. Varkas G, Thevissen K, De Brabanter G, et al. An induction or flare of arthritis and/or sacroiliitis by vedolizumab in inflammatory bowel disease: a case series. Ann Rheum Dis $2017 ; 76: 878-881$.

111. Tadbiri S, Grimaud JC, Peyrin-Biroulet L, et al. Efficacy of vedolizumab on extraintestinal manifestation in patients with inflammatory bowel disease: a post-hoc analysis of the OBSERV-IBD cohort from the GETAID. J Crohn's Colitis 2017;11:S42.

112. Feagan BG, Sandborn WJ, Colombel JF, et al. Effect of Vedolizumab Treatment on Extraintestinal Manifestations in Patients with Crohn's Disease: A Gemini 2 Post hoc Analysis. Gastroenterology 2017;152:S597.

113. Orlando A, Orlando R, Ciccia F, et al. Clinical benefit of vedolizumab on articular manifestations in patients with active spondyloarthritis associated with inflammatory bowel disease. Ann Rheum Dis 2017;76:e31.

DOI: 10.1136/annrheumdis-2016-211011

114. A Study to Evaluate the Safety and Efficacy of Ustekinumab Induction and Maintenance Therapy in Participants With Moderately to Severely Active Ulcerative Colitis (UNIFI). (cited 2017 June 21). Available at: https://clinicaltrials.gov/ct2/show/NCT02407236.

115. Poddubnyy D, Hermann K-GA, Callhoff J, et al. Ustekinumab for the treatment of patients with active ankylosing spondylitis: results of a 28 -week, prospective, open- 
label, proof-of-concept study (TOPAS). Ann Rheum Dis 2014;73:817-23.

116. A Study to Evaluate the Efficacy and Safety of Ustekinumab in the Treatment of AntiTNF $\alpha$ Naive Participants With Active Radiographic Axial Spondyloarthritis. (cited 2017 June 21). Available from: https://clinicaltrials.gov/ct2/show/NCT02437162.

117. An Efficacy and Safety Study of Ustekinumab in Participants With Active Nonradiographic Axial Spondyloarthritis. (cited 2017 June 21). Available from: https://clinicaltrials.gov/ct2/show/NCT02407223.

118. Olivera P, Danese S, Peyrin-Biroulet L. Next generation of small molecules in inflammatory bowel disease. Gut 2017;66:199-209.

119. Olivera P, Danese S, Peyrin-Biroulet L. JAK inhibition in inflammatory bowel disease. Expert Rev Clin Immunol 2017:1-11.

120. Sandborn WJ, Ghosh S, Panes J, et al. A phase 2 study of tofacitinib, an oral Janus kinase inhibitor, in patients with Crohn's disease. Clin Gastroenterol Hepatol 2014;12:1485-93.e2.

121. Panés J, Sandborn WJ, Schreiber S, et al. Tofacitinib for induction and maintenance therapy of Crohn's disease: results of two phase IIb randomised placebo-controlled trials. Gut 2017;66:1049-1059.

-122. Sandborn WJ, Su C, Sands BE, et al. Tofacitinib as Induction and Maintenance Therapy for Ulcerative Colitis. N Engl J Med 2017;376:1723-1736.

\section{Pivotal trial providing evidence for the use of tofacitinib in UC.}

123. Vermeire S, Schreiber S, Petryka R, et al. Clinical remission in patients with moderateto-severe Crohn's disease treated with filgotinib (the FITZROY study): results from a phase 2, double-blind, randomised, placebo-controlled trial. Lancet 2017;389:266-275.

124. Sandborn WJ, Feagan BG, Panes J, et al. Safety and Efficacy of ABT-494 (Upadacitinib), an Oral Jak1 Inhibitor, as Induction Therapy in Patients with Crohn's 
Disease: Results from Celest. Gastroenterology 2017;152:S1308-1309.

125. De Vries LCS, Wildenberg ME, De Jonge WJ, et al. The Future of Janus Kinase Inhibitors in Inflammatory Bowel Disease. J Crohn's Colitis 2017.

DOI: $10.1093 /$ ecco-jcc/jjx003

126. van der Heijde D, Deodhar A, Wei JC, et al. Tofacitinib in patients with ankylosing spondylitis: a phase II, 16-week, randomised, placebo-controlled, dose-ranging study. Ann Rheum Dis 2017; 76(8):1340-1347. DOI: 10.1136/annrheumdis-2016-210322

127. Armuzzi A, Felice C, Lubrano E, et al. Multidisciplinary management of patients with coexisting inflammatory bowel disease and spondyloarthritis: A Delphi consensus among Italian experts. Dig Liver Dis 2017;S1590-8658(17):30934-9.

DOI: $10.1016 /$ j.dld.2017.06.004

128. Moon W, Loftus E V. Review article: recent advances in pharmacogenetics and pharmacokinetics for safe and effective thiopurine therapy in inflammatory bowel disease. Aliment Pharmacol Ther 2016;43:863-883.

129. Macaluso FS, Renna S, Maida M, et al. Tolerability profile of thiopurines in inflammatory bowel disease: a prospective experience. Scand J Gastroenterol 2017:17. DOI: $10.1080 / 00365521.2017 .1333626$

130. Murphy SJ, Wang L, Anderson LA, et al. Withdrawal of corticosteroids in inflammatory bowel disease patients after dependency periods ranging from 2 to 45 years: a proposed method. Aliment Pharmacol Ther 2009;30:1078-1086.

131. Fiorino G, Danese S, Pariente B, et al. Paradoxical immune-mediated inflammation in inflammatory bowel disease patients receiving anti-TNF- $\alpha$ agents. Autoimmun Rev $2014 ; 13: 15-9$.

132. Thiebault H, Boyard-Lasselin P, Guignant C, et al. Paradoxical articular manifestations in patients with inflammatory bowel diseases treated with infliximab. Eur J 
Gastroenterol Hepatol 2016;28:876-881.

133. Klingenstein G, Levy RN, Kornbluth A, et al. Inflammatory bowel disease related osteonecrosis: report of a large series with a review of the literature. Aliment Pharmacol Ther 2005;21:243-249.

134. Yanai H, Shuster D, Calabrese E, et al. The incidence and predictors of lupus-like reaction in patients with IBD treated with anti-TNF therapies. Inflamm Bowel Dis 2013;19:2778-86.

135. Forrest K, Symmons D, Foster P. Systematic review: is ingestion of paracetamol or non-steroidal anti-inflammatory drugs associated with exacerbations of inflammatory bowel disease? Aliment Pharmacol Ther 2004;20:1035-43.

136. Takeuchi K, Smale S, Premchand P, et al. Prevalence and mechanism of nonsteroidal anti-inflammatory drug-induced clinical relapse in patients with inflammatory bowel disease. Clin Gastroenterol Hepatol 2006;4:196-202.

137. Miedany Y El, Youssef S, Ahmed I, et al. The gastrointestinal safety and effect on disease activity of etoricoxib, a selective cox-2 inhibitor in inflammatory bowel diseases. Am J Gastroenterol 2006;101:311-7.

138. Sandborn WJ, Stenson WF, Brynskov J, et al. Safety of celecoxib in patients with ulcerative colitis in remission: a randomized, placebo-controlled, pilot study. Clin Gastroenterol Hepatol 2006;4:203-11.

139. Bonner GF, Fakhri A, Vennamaneni SR. A long-term cohort study of nonsteroidal antiinflammatory drug use and disease activity in outpatients with inflammatory bowel disease. Inflamm Bowel Dis 2004;10:751-7.

140. Barthel D, Ganser G, Kuester R-M, et al. Inflammatory Bowel Disease in Juvenile Idiopathic Arthritis Patients Treated with Biologics. J Rheumatol 2015;42:2160-2165.

141. Bieber A, Fawaz A, Novofastovski I, et al. Antitumor Necrosis Factor- $\alpha$ Therapy 
Associated with Inflammatory Bowel Disease: Three Cases and a Systematic Literature Review. J Rheumatol 2017;44(7):1088-1095. DOI: 10.3899/jrheum.160952

142. Peyrin-Biroulet L, Assche G Van, Gomez-Ulloa D, et al. Systematic Review of Tumor Necrosis Factor Antagonists in Extraintestinal Manifestations in Inflammatory Bowel Disease. Clin Gastroenterol Hepatol 2017;15:25-36.e27.

143. Ciccia F, Guggino G, Rizzo A, et al. Type 3 innate lymphoid cells producing IL-17 and IL-22 are expanded in the gut, in the peripheral blood, synovial fluid and bone marrow of patients with ankylosing spondylitis. Ann Rheum Dis 2015;74:1739-47.

144. Van De Wiele T, Praet JT Van, Marzorati M, et al. How the microbiota shapes rheumatic diseases. Nat Rev Rheumatol 2016;12:398-411.

DOI: $10.1038 /$ nrrheum.2016.85 
Figure 1: Pharmacologic treatment options in patients with IBD and SpA.

Legend: CD: Crohn's disease; JAK: janus kinase; NSAIDs: non-steroidal anti-inflammatory drugs; SpA: spondyloarthritis; UC: ulcerative colitis.

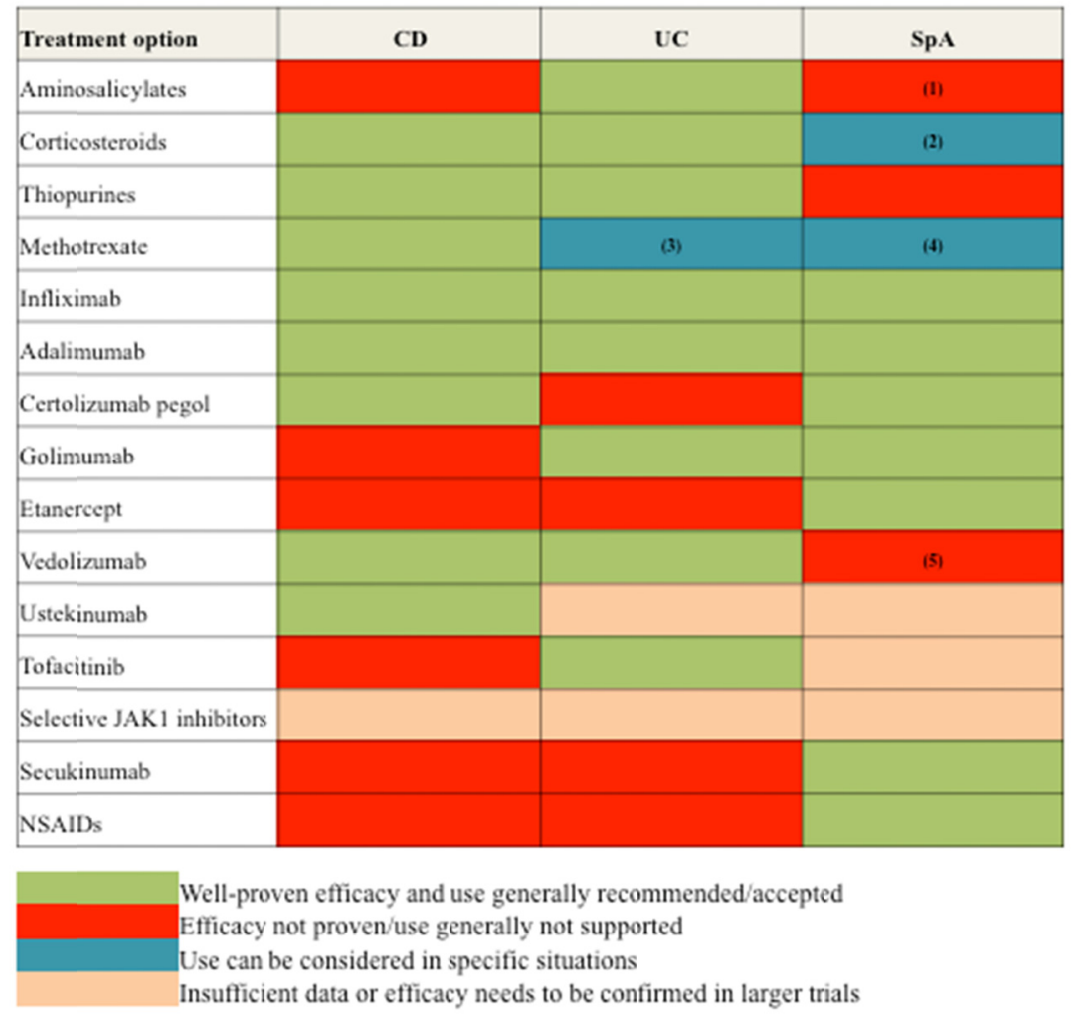

(1) Sulfasalazine can be considered in patients with peripheral SpA, but not in axial SpA.

(2) Local corticosteroid injection is a valuable option in peripheral $\mathrm{SpA}$; systemic corticosteroids can only be considered as a short bridge to other therapies.

(3) Methotrexate can be considered in UC patients with steroid-dependent disease.

(4) Methotrexate can be considered in patients with peripheral $\mathrm{SpA}$, but not in axial $\mathrm{SpA}$.

(5) Vedolizumab is not a specific treatment option for $\mathrm{SpA}$, but might improve IBD-related arthritis. 
Table 1: ASAS classification criteria for peripheral and axial $\mathrm{SpA}^{22,23}$.

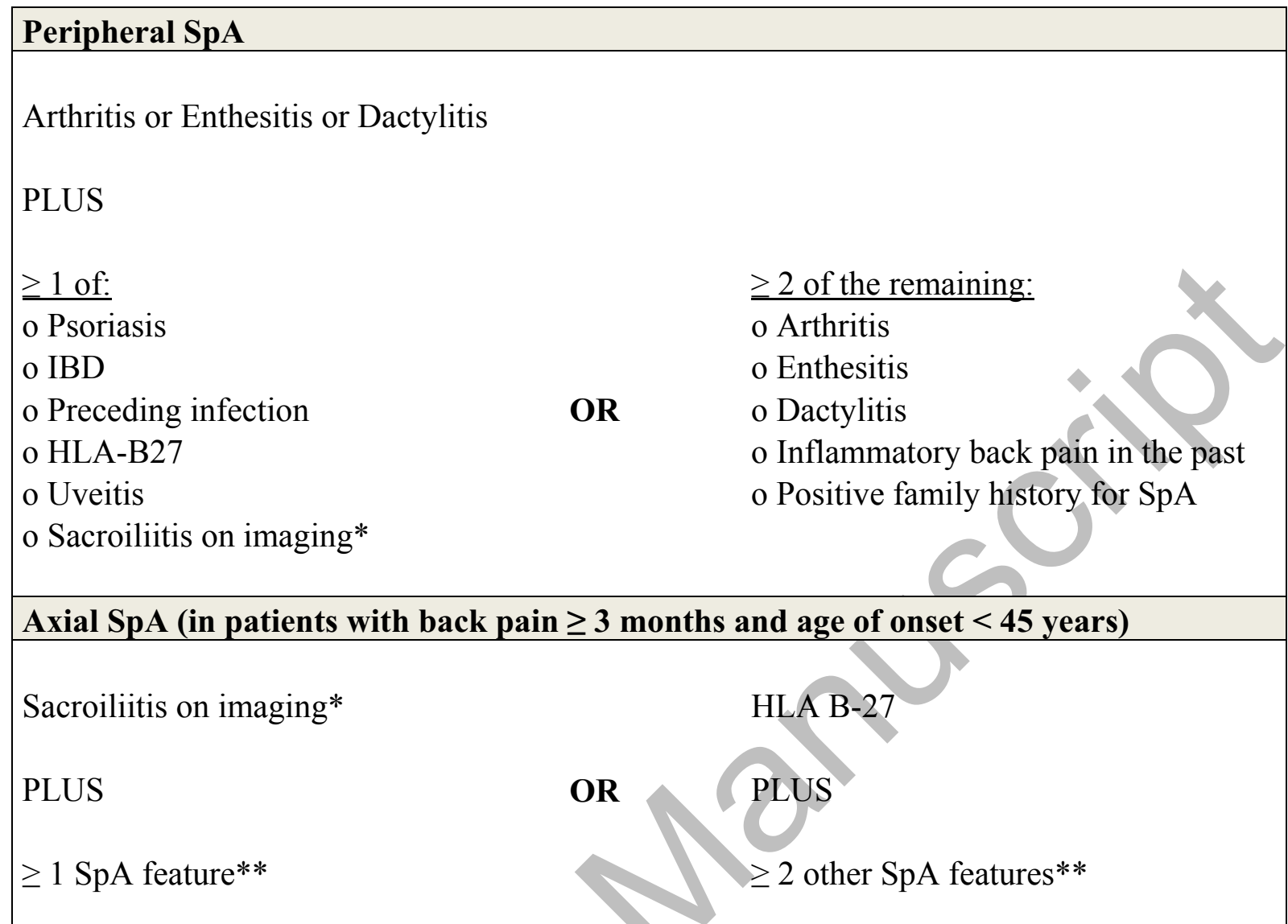

* Sacroiliitis on imaging:

- Active (acute) inflammation on MRI highly suggestive of sacroiliitis associated with SpA OR

- Definite radiographic sacroiliitis according to modified New York criteria

** SpA features:

- Inflammatory back pain

- Arthritis

- Enthesitis (heel)

- Uveitis

- Dactylitis

- Psoriasis

- $\mathrm{CD} / \mathrm{UC}$

- Good response to NSAIDs

- Family history of SpA

- HLA-B27

- Elevated CRP 
Table 2: Classification of IBD-related arthritis according to ECCO consensus (2016) ${ }^{3}$.

\begin{tabular}{|l|l|l|}
\hline Localisation & Disease characteristics & Subtypes \\
\hline Peripheral & - Signs of inflammation & $\underline{\text { Type } 1}$ \\
& and & - Affecting $\leq 5$ joints \\
& - Exclusion of other specific forms of arthritis & - Predominantly lower limbs \\
& & - Mostly acute and self-limiting \\
& & - Parallels IBD activity \\
& & Type 2 \\
& & - Affecting $>5$ joints \\
& features of sacroiliitis & - Predominantly upper limbs \\
& - Inflammatory back pain & - Can persist months/years \\
& and & - Independently from IBD activity \\
\hline
\end{tabular}


Table 3: Diagnostic clues for referral of the IBD patient to the rheumatologist and for referral of the SpA patient to the gastroenterologist ${ }^{4,5}$.

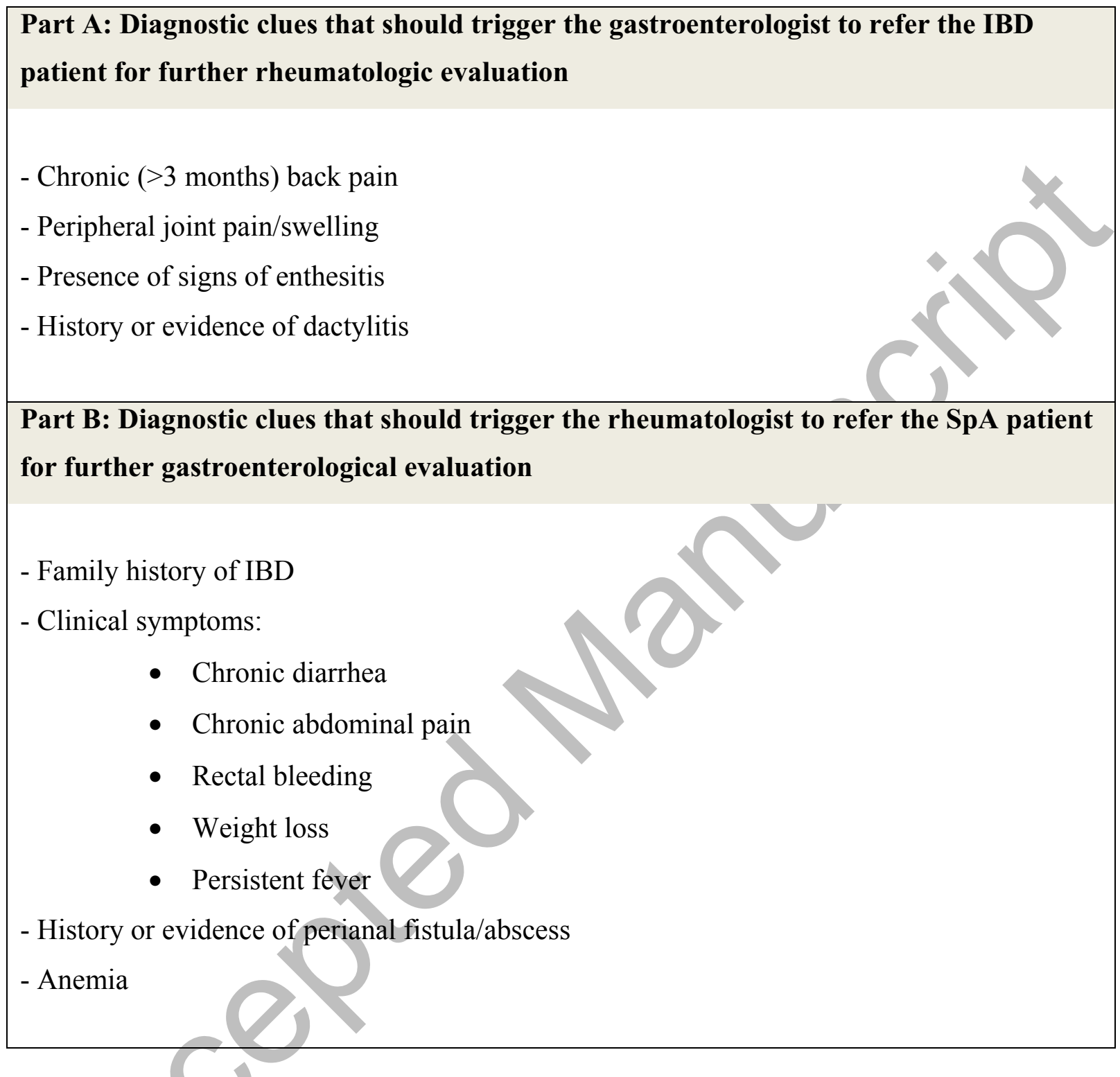


Table 4: Key components of the current available treatment guidelines in IBD patients with coexisting SpA.

Olivieri et al. (2014)

Peripheral $\mathrm{SpA}(\leq 4$ joints, enthesitis, dactylitis) and active IBD

o Systemic steroids and/or sulfasalazine according to IBD indications.

o Anti-TNF according to IBD guidelines.

o Consider stopping anti-TNF only after complete IBD remission.

\section{Peripheral SpA ( $>4$ joints) and active IBD}

o Systemic steroids and/or sulfasalazine according to IBD indications.

o NSAIDs should be avoided.

o Anti-TNF according to IBD guidelines.

o Consider stopping anti-TNF only after complete IBD remission.

\section{Peripheral SpA and IBD in remission}

o Local steroid injections, short- term ( $\leq 15$ days) NSAIDs and oral sulfasalazine are appropiate options in peripheral oligoarthritis ( $\leq 4$ joints, enthesitis, dactylitis).

o Short-term ( $\leq 15$ days) NSAIDs/systemic steroids may be considered as a bridge to oral sulfasalazine in peripheral polyarthritis ( $>4$ joints).

o Anti-TNF according to rheumatological indications.

o Anti-TNF can be gradually suspended according to rheumatologist's opinion in case of prolonged remission.

\section{Axial SpA and active IBD}

o Rehabilitation therapy according to ASAS recommendations.

o Anti-TNF according to IBD guidelines.

o Anti-TNF long-term treatment according to axial SpA treatment recommendations only after complete IBD remission.

\section{Axial SpA and IBD in remission}

o Rehabilitation therapy according to ASAS recommendations.

o NSAIDs can be used only short-term ( $\leq 15$ days).

o Anti-TNF according to ASAS guidelines.

o Anti-TNF long-term treatment according to ASAS ${ }^{\circ}$ guidelines.

\section{ECCO consensus (2016)}

\section{Peripheral SpA}

o Treatment of underlying gut inflammation is often sufficient to treat peripheral arthritis.

o Short-term NSAID or local steroid injection can be used to provide symptomatic relief.

o Short-term oral corticosteroïds are effective but should be discontinued as soon as practicable.

o Sulfasalazine and methotrexate may have a role the treatment.

o Anti-TNF therapy is appropiate and effective in resistant cases.

\section{Axial SpA}

o Intensive physiotherapy is effective.

o Short-term NSAIDs is effective but long-term treatment with NSAIDs is not recommended.

o Sulfasalazine and methotrexate are of limited efficacy.

o Anti-TNF is the preferred treatment for those intolerant or refractory to NSAIDs. 